\title{
Standardized exercise tests in horses: current situation and future perspectives
}

\author{
Inspanningstesten bij paarden: \\ stand van zaken en toekomstperspectieven
}

L. de Mare, B. Boshuizen, L. Plancke, C. de Meeus, M. de Bruijn, C. Delesalle

Department of Comparative Physiology, Faculty of Veterinary Medicine, Ghent University, Salisburylaan 133, Belgium

Catherine.Delesalle@Ugent.be

\begin{abstract}
$\Lambda_{\text {bStract }}$
The purpose of this literature review is to clarify how exercise capacity can be measured in horses and which standardized exercise tests (SETs) exist. In this review, the measurement of the exercise capacity of horses is discussed and the standardized exercise tests (SET) are described. Two main types of SETs are used. Laboratory or treadmill tests are easy to standardize and provide more options to use all kinds of measuring devices, since the horse stays on the treadmill. On the other hand, field tests are conducted under the natural conditions associated with the specific sports discipline, and are easier to implement in the training schedule. However, field tests encompass interfering variables, such as weather conditions, ground surface conditions and the rider or jockey. Several variables are measured in order to calculate the fitness level which may be expressed by different parameters, such as V200 (speed at a heart rate of 200 beats per minute), Vla4 (speed at a blood lactic acid level of $4 \mathrm{mmol} / \mathrm{L}$ ) and VO2max (maximum oxygen uptake).
\end{abstract}

\section{SAMENVATTING}

In dit overzichtsartikel wordt beschreven hoe inspanningscapaciteit bij het sportpaard kan worden gemeten en welke gestandaardiseerde inspanningstesten (SET) bestaan. Er worden twee types SETs gebruikt: de gemakkelijk standaardiseerbare, lopende bandtest en de veldtesten, waarbij de gebruikelijke omstandigheden beter nagebootst kunnen worden, maar waardoor meer variabiliteit in de metingen ontstaat. Er worden verschillende parameters gemeten, zoals de snelheid bij een hartslag van 200 slagen/min (V200), de snelheid waarbij de bloed-lactaatgehaltes boven $4 \mathrm{mmol} / \mathrm{L}$ stijgen (Vla4) en de maximale zuurstofopname (VO2max).

\section{INTRODUCTION}

The increasing professionalism of different equine sports disciplines entails that an increasing load of training and competition is imposed upon sport horses, both at international competition level and at the level of a growing group of semi-professional, recreative riders. However, in great contrast with human sports training physiology, the training of sport horses is still predominantly performed based upon 'gut feeling'. Indeed, science about training of horses in different sports disciplines is still in its infancy compared to the techniques that are routinely applied in the training of elite human athletes. Fitness level evaluation of elite human athletes is performed during controlled, standardized exercise tests that are adapted for specific sports disciplines and during which physiological parameters are monitored, such as heart rate (HR), blood lactic acid, respiratory parameters, maximum power output, maximum oxygen uptake (VO2max), and in some cases, the assessment of muscle biopsies. These tests can be applied either in laboratoriy conditions on either a treadmill or cycle ergometers, or outdoors in the field, for instance using a back pack equipped with a mobile VO2max analyzer.

Professional equine trainers use GPS equipped heart rate monitors to continuously assess HR and velocity (Figures 1A and 1B) throughout training. The newest devices even indicate the grade of inclination of the terrain upon which the training is performed. At given time points, standardized exercise tests can be applied; however, knowledge about these siverse SET tests is very scattered. An important issue is which type of SET applies best for which type of sports discipline. A standardbred used for trotting requires another type of performance capacity than 

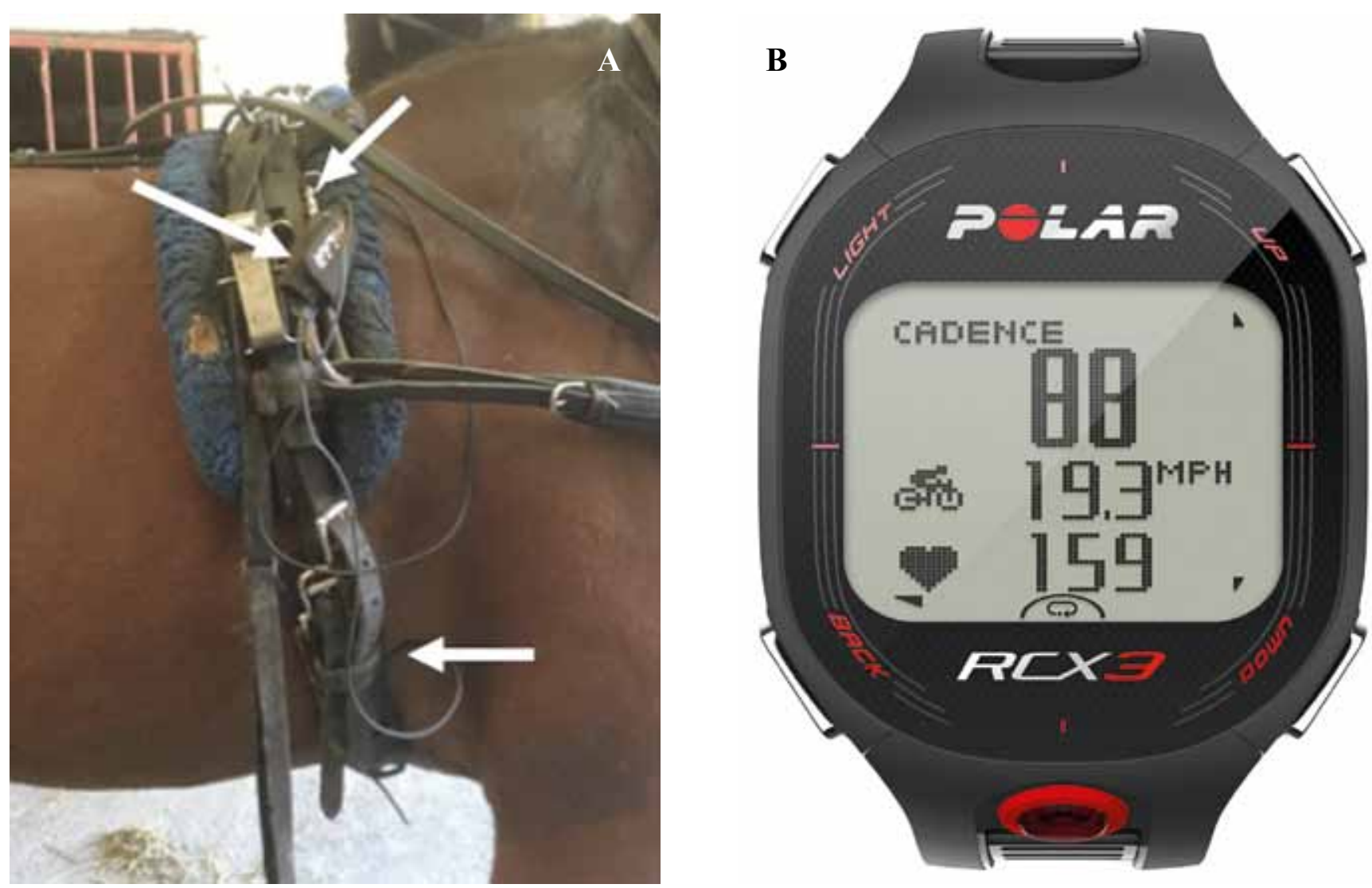

Figures 1A and 1B. GPS equipped heart rate monitors (the two sensors are indicated with the arrows). (Left panel) and GPS equipped watch that depicts heart rate and velocity in the horses throughout exercise.

a show jumper. Besides performance capacity, there is also the factor skills. Show jumping and dressage require the horse to be able to demonstrate a certain set of skills in order to perform optimal competition. When it comes to measuring physiological parameters throughout equine SETs, both HR and velocity monitoring are very feasible. Longitudinal follow-up of blood lactic acid levels throughout a SET is also quite feasible, since hand-held lactic acid analyzers are available for horses. However, when it comes to measuring maximal power output, it is impossible to put a horse on a Wattbike. In addition, measuring VO2max is quite challenging: many efforts have been made by several research groups to achieve this; however, measuring VO2max in horses under field conditions retrieves lower maximum values than under laboratory conditions (Van Erck et al., 2007). In all these equine studies, human VO2maximum analyzers were used, which have been adapted for the use in horses. However, keeping in mind that a human athlete in full action displaces approximately $60 \mathrm{~L}$ of air per minute versus a $500-\mathrm{kg}$ horse approximately $1500 \mathrm{~L}$ per minute, most probably renders sampling methods and frequencies applied in human analyzers, unsuitable and simply ineffective in horses (Figures $1 \mathrm{~A}$ and 1B). However, more research is needed with that respect.

Consequently, two important issues should be addressed when it comes to performance capacity evalu- ation of equine athletes: (1) the inability to objectively grade and measure important physiological parameters, such as maximum power output and VO2max, and (2) the diversity of SETs that are currently being applied. Often, there is a lack of scientific evidence with respect to their validation, repeatability and suitability for the specific sports discipline, in which the horse needs to perform.

There are two main types of exercise tests to assess the aerobic and anaerobic capacity of horses: laboratory exercise tests (treadmill tests) and field exercise tests. Three criteria should be taken into account when setting up an exercise test. Validity means that the protocol simulates the work required for the specific sports discipline. Achieving a reasonable validity is easier for SETs in the field than on a treadmill because field tests better approach the real situation, in which the horse needs to compete (Franklin et al., 2014; Allen et al., 2016). The second criterium is repeatability, meaning that a specific SET should reveal similar results when executed within the short-time interval of a few days. Standardization of a treadmill test is easier to achieve. However, despite the influence of factors such as the driver, track condition and weather conditions (Franklin et al., 2014; Allen et al., 2016), several studies have shown acceptable repeatability for field SETs as well (Courouce, 1999; Dubreucq et al., 1995). Finally, the SETs needs to show sufficient sensitivity, which means that the protocol should be able 


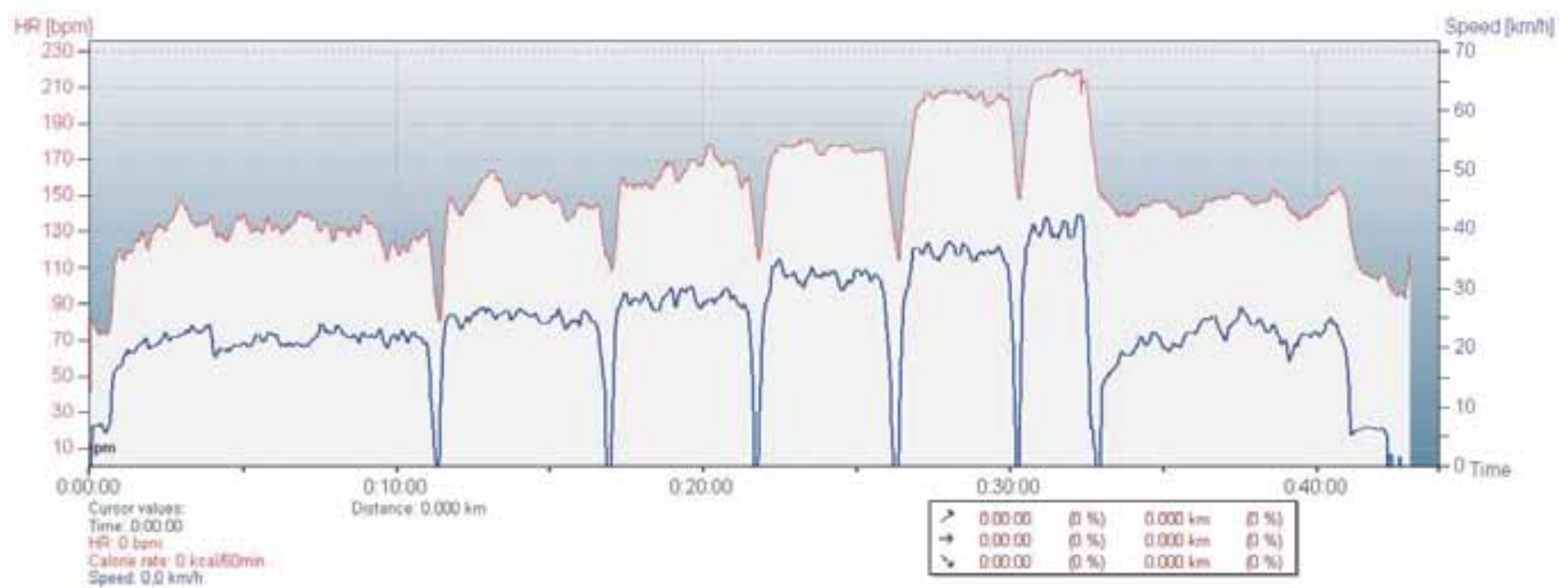

Figure 2. HR (red) and velocity (blue) during incremental SET. Each episode represents an exercise bout (interval).

to detect small but significant changes in performance capacity throughout time (Franklin et al., 2014; Allen et al., 2016).

Apart from the aforementioned criteria, field tests are also more easily introduced into the training schedule than treadmill tests, which require transportation of the horse to a designated facility. Additionally, it often takes a few days to get an unacquainted horse familiar with running on a high-speed treadmill.

The exercise capacity of a horse is deduced from the maximum amount of physical effort a horse can sustain during a certain time interval. Exercise tests can be used to compare horses, but also to follow-up training progress of a horse over time. The exercise capacity of a horse is currently assessed by means of measuring series of specific physiological parameters, such as heart rate, blood lactic acid levels and velocity during SETs. The most commonly used parameters are VLa4, i.e. the speed at which the blood lactate concentration reaches $4 \mathrm{mmol} / \mathrm{L}$, the 'artificially determined' anaerobic threshold and V200, i.e. the speed at which the heart rate reaches 200 beats per minute. VLa4 and V200 are theoretically almost equal in healthy, well-trained horses, although V200 is less trainable and heart rate fluctuates more easily than lactate because of for example mental status or physical discomfort. In a poorly performing horse for example, where V200 is significantly lower than VLa4, a (subclinical) musculoskeletal injury may be suspected. A decrease in VLa4 on the other hand is more often associated with respiratory disease. When designing an exercise testing protocol, several important features should be kept in mind (Hodgson et al., 2014; Franklin et al., 2014; Courouce, 1999; Allen et al., 2016): 1. Velocity and distances have to be controlled and should be as constant as possible, including track- and weather conditions. 2. Each step of an (incremental) exercise test should persist long enough to obtain steady state of the physiological parameters (HR, Lactate): on average 3-5 minutes. 3. Due to lac- tate efflux from muscles to blood, the lactate concentration in blood varies according to the moment of sampling. Therefore, it is important to obtain samples at fixed moments. 4. The number of steps and the degree of increment should be standardized. 5. To allow for correct comparison of data between horses, it is necessary to take into account the breed, age, fitness level and training history of the horses. Studies with French standardbreds showed an increase of VLa2, VLa4 and V200 according to increases in age or the training status of the horses (Leleu et al., 2005; Courouce et al., 2002).

The preferable testing protocol should be suitable to test the performance capacity that is needed to compete successfully in a certain sports discipline. It is obvious that a quarter horse that competes at barrel races, needs more anaerobic capacity than an endurance horse (Franklin et al., 2014). The different protocols can be divided in incremental protocols, which consist of multiple steps of increasing intensity (velocity) and in single-step protocols.

\section{Incremental exercise test}

The incremental exercise test is advised to obtain a first insight into the performance capacity of a horse. By performing the sequential incremental steps, the horse is evaluated throughout a wide range of speeds. Before starting with the exercise, a warming-up consisting of trotting or slow cantering is required to prevent injuries (Franklin et al., 2014). During the incremental exercise test, every step ('heat') needs to be maintained for three to five minutes, in order to obtain a steady state in heart rate (Figure 2). Submaximal exercise is continued until the horse reaches a preset HR or blood lactate concentration to determine e.g. V200 and Vla4. To determine maximal exercise capacity, the speed is slowly increased until the horse can't maintain the speed anymore. Maximum HR and blood lactic acid levels are 


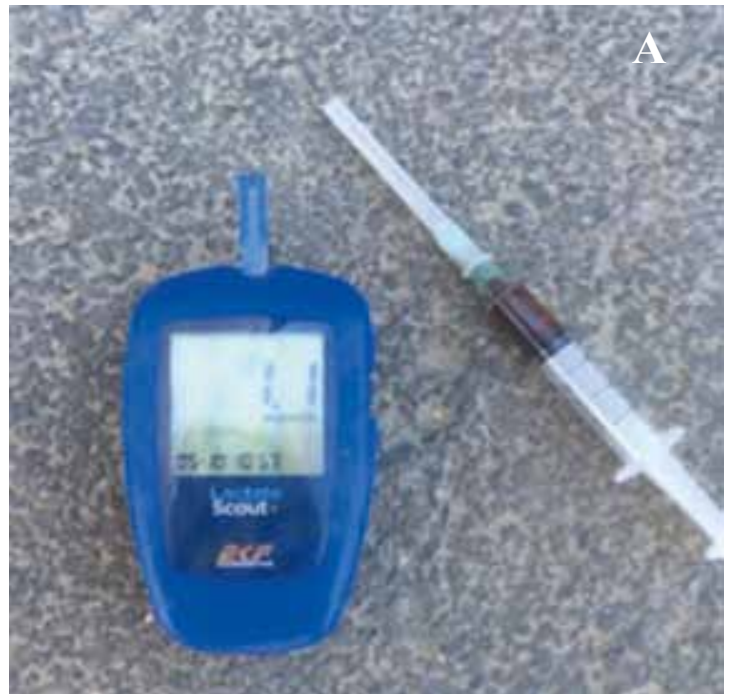

Figure 3A. Handheld lactic acid measuring device. 3B. The relation between HR (blue curve) and lactic acid concentration in blood (green line) during increasing speeds (X-axis).

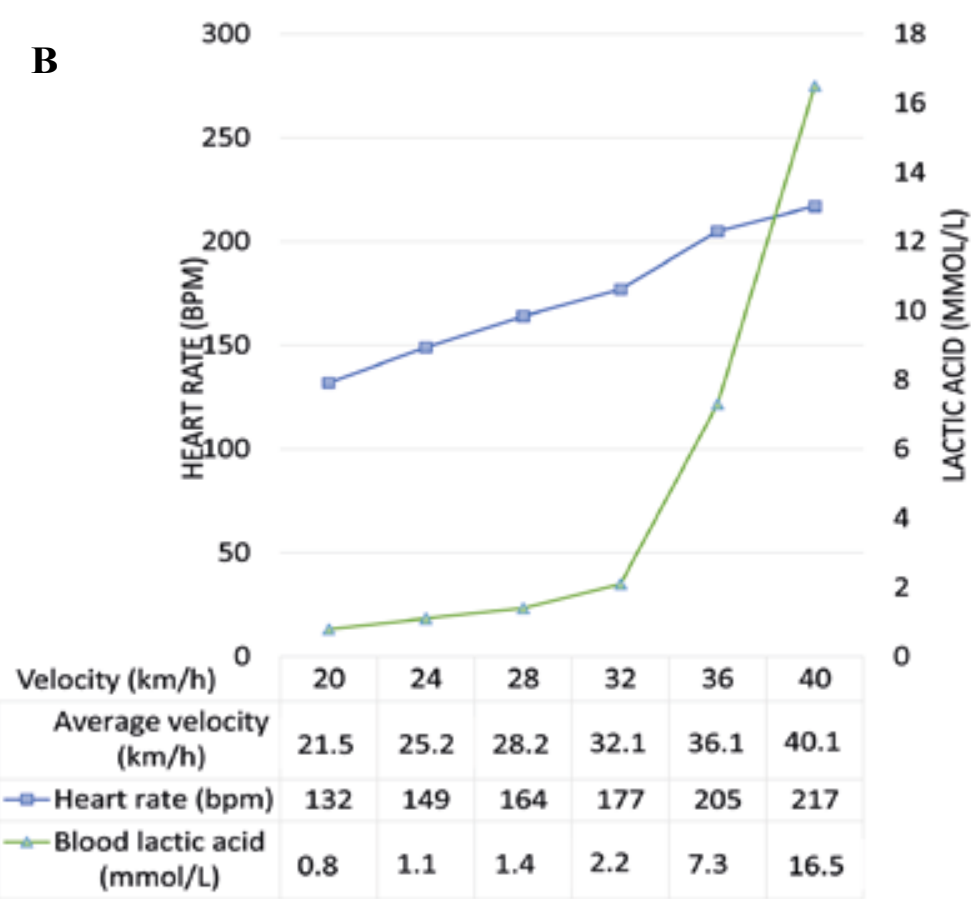

mental exercise test in thoroughbred horses without the use of protocols with strict adherence to steps of a constant speed. Commercial HR monitors and a stopwatch every $200 \mathrm{~m}$ to measure the velocity were used. Trainers will adopt this technique more easily, because it is easier to implement this test in their training schedules (Kobayashi et al., 1999). The parameters derived from submaximal incremental exercise tests (VLa4, V200) are correlated with racing performance in both thoroughbreds and standardbreds (see below).

\section{Single step (high-speed) exercise test}

A single step (high-speed) exercise test is used in horses of which there is already a view on exercise capacity. The intended speed depends on the track length, track conditions and the training level of the tested horses (Evans, 2000). In this way, the performance parameters VO2max and HRmax (Allen et al., 2016) can be calculated and the differences between poor and superior performers can be verified. An average speed of $41.4-45 \mathrm{~km} / \mathrm{h}$ is suitable for testing Standardbred racehorses and a speed of 48-54 $\mathrm{km} / \mathrm{h}$ for Thoroughbreds. Evans et al. (1993) showed a correlation over 0.6 between blood lactic acid concentration and racing performance of Thoroughbreds 2 minutes after a treadmill exercise at $36 \mathrm{~km} / \mathrm{h}$. The measured blood lactic acid concentrations decreased gradually during training with a concomitant increase of VLa4. This type of exercise tests avoids necessity for multiple sampling and the associated breaks that are required in incremental exercise tests in the field.

The development of a high-speed single step test (Hodgson et al., 2014) can replace the incremental exercise test, which does not represent racing condiHR-velocity relationship in the field with an incre- 
tions (Allen et al., 2016). Horses are subjected to an exercise test at near maximal speeds/intensities. It is an ideal test to determine the anaerobic capacity of horses. However, several studies failed to demonstrate a significant correlation between these anaerobic indices and racing performance, in contrast to the information obtained in an incremental exercise test, e.g. VLa4 (Evans, 2000; Hodgson et al., 2014).

\section{OVERVIEW OF SETS FOR DIFFERENT SPORTS DISCIPLINES}

There are important differences in exercise capacity between horse breeds. However, it is important to realize that each sports discipline requires its specific set of capacities and its own stamina level. In Table 2 , an overview of the different SET protocols used in different equestrian disciplines are shown.

\section{Thoroughbred racehorses}

The racing performance of thoroughbred racehorses depends on both their aerobic and anaerobic capacities. Additionally, thoroughbreds have higher V200 values than other breeds (Vermeulen et al., 2006; Wolter et al., 1996). During incremental exercise tests, a reproducible HR-speed relationship may be determined (Munsters et al., 2014). The derived indices of exercise capacity, like V200, Vla4, VHRmax and Vmax, provide a view on exercise capacity (Vermeulen et al., 2006; Kobayashi et al., 1999). VO2max and VHRmax are correlated with the racing performance in thoroughbreds (Harkins et al., 1993; Wolter et al., 1996). Incremental SETs are less suitable for thoroughbred horses, because of the difficulty to make them run at constant speeds and to control track conditions (Courouce et al., 2013). Therefore, a single-bout exercise test seems more suitable to assess performance capacity in thoroughbreds. Single-step exercise tests that take into account the variability

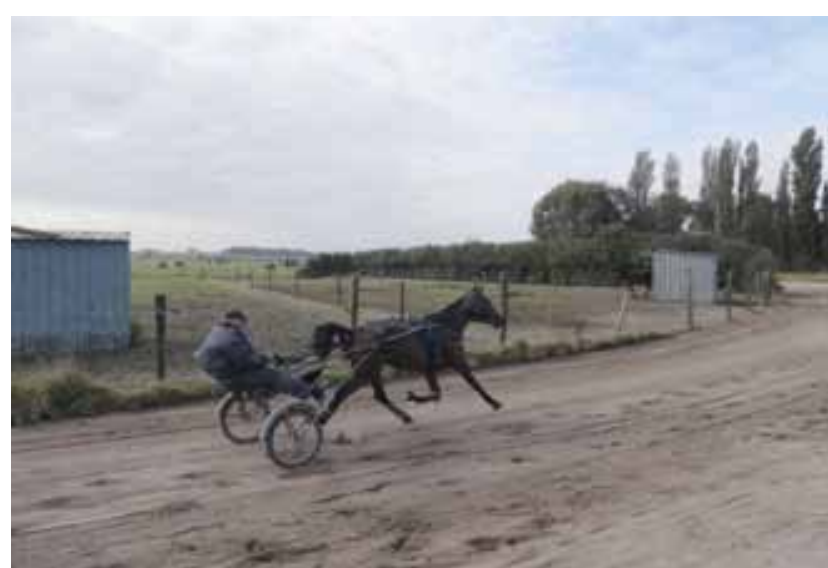

Figure 4. Harness trotting during training.

of speed and that are based on the calculation of differences between measured and predicted lactate concentration (track specific lines of best fit), have potential for fitness evaluation during field exercise tests (Wolter et al., 1996). Superior English thoroughbreds had lower blood lactic acid concentrations after a single-bout exercise (Evans, 2000). Some studies state that lactic acid indices are a superior predictor of racing ability in thoroughbred racehorses (Evans, 2000). Vla4 is very important for thoroughbreds since anaerobic metabolism is of major importance in thoroughbred racing.

\section{Standardbreds: trotters and pacers}

Standardbreds in France run trotting races of 2000$4000 \mathrm{~m}$, while American standardbred racehorses run races of 1 mile $(1600 \mathrm{~m})$ (Leleu etal., 2005). In a study in which the aerobic capacity between two groups of standardbred horses was compared, the fastest group showed a higher VO2max and completed a higher number of workloads before fatigue than the slowest group, indicating that racing performance is mainly dependent on the aerobic capacity of standardbreds (Evans, 2007).

Table 1. Incremental exercise tests (from Franklin and Allen, 2014).

\begin{tabular}{|c|c|c|}
\hline Exercise test & Incline & Time/speed \\
\hline *Incremental exercise test for Thoroughbred & $10 \%$ & 1 minute at 6,8 and $10 \mathrm{~m} / \mathrm{s}$, followed by \\
\hline National Hunt and flat horses $>1$ mile & & $1 \mathrm{~m} / \mathrm{s}$ increases at 1 minute intervals until fatigue \\
\hline $\begin{array}{l}\text { *High-speed test for Thoroughbred flat, } \\
\text { sprint horses }\end{array}$ & $10 \%$ & Rapidly increase to $11-12 \mathrm{~m} / \mathrm{s}$, stay at this speed until fatigue \\
\hline $\begin{array}{l}{ }^{1} \text { High-speed test for Thoroughbred flat horses } \\
\text { and Standardbreds }\end{array}$ & $0-4 \%$ & Rapidly increase to $11-14,5 \mathrm{~m} / \mathrm{s}$, stay at this speed until fatigue \\
\hline${ }^{2}$ Incremental exercise test for Standardbreds & $0-4 \%$ & $\begin{array}{l}\text { Three steps of } 2-3 \text { minutes each performed at speeds of } 7,9 \\
\text { and } 10,5 \text { or } 11 \mathrm{~m} / \mathrm{s} \text {. Between each step horses recover for } \\
1-2 \text { minutes at walk }(1,8 \mathrm{~m} / \mathrm{s}) \text { or trot }(4,5 \mathrm{~m} / \mathrm{s})\end{array}$ \\
\hline
\end{tabular}

*Typical exercise tests performed at the University of Bristol Equine Sports Medicine centre.

${ }^{1}$ Data from Parente et al. 1996 ; Durando et al., 2002 and Strand et al., 2012.

${ }^{2}$ Data from Richard et al. 2010 and Courouce-Malblanc et al., 2000. 
Table 2. Overview of different SET protocols per discipline.

\begin{tabular}{|c|c|c|}
\hline $\begin{array}{l}\text { Discipline/breed (n) } \\
\text { (Track/Treadmill/ } \\
\text { Riding arena) }\end{array}$ & Protocol & Reference \\
\hline $\begin{array}{l}\text { Racing Thoroughbreds (112) } \\
\text { (Track) }\end{array}$ & $\begin{array}{l}\text { Incremental } \\
1000 \mathrm{~m} \text { trotting at } 250 \mathrm{~m} / \mathrm{min} \text {, then galloping at } 400,460,550,660 \mathrm{~m} / \mathrm{min} \text { for } 600-800 \mathrm{~m}\end{array}$ & Kobayashi et al., 1999 \\
\hline $\begin{array}{l}\text { Racing Thoroughbreds (9) } \\
\text { (Track) }\end{array}$ & $\begin{array}{l}2 \text {-step } \\
600 \mathrm{~m} / \mathrm{min} \text { and } 80-90 \% \text { max. speed for } 1038 \mathrm{~m}\end{array}$ & Von Wittke et al., 1994 \\
\hline $\begin{array}{l}\text { Racing Thoroughbreds (46) } \\
\text { (Track) }\end{array}$ & $\begin{array}{l}\text { Single step } \\
1000 \mathrm{~m} \text { warm-up (slow trot), } 780-960 \mathrm{~m} / \mathrm{min} \text { (gallop, speed used in training) for } 800 \mathrm{~m}\end{array}$ & Davie and Evans, 2000 \\
\hline $\begin{array}{l}\text { Racing Thorougbhreds ( } 8) \\
\text { (Track) }\end{array}$ & $\begin{array}{l}\text { Incremental } \\
\text { warm up, } 3 \times 3 \mathrm{~min} \text { : canter, gallop, faster gallop + recovery periods in between }\end{array}$ & Wolter et al., 1996 \\
\hline $\begin{array}{l}\text { Racing Thoroughbreds } \\
\text { (Track) }\end{array}$ & Warm-up trot + fast gallops in the field al velocities of $900-960 \mathrm{~m} / \mathrm{min}$ & $\begin{array}{l}\text { Gramkow and Evans, } \\
2006\end{array}$ \\
\hline $\begin{array}{l}\text { Racing Thoroughbreds (12) } \\
\text { (Track) }\end{array}$ & A fast exercise training session with max. speeds between 16.7 and $19.4 \mathrm{~m} / \mathrm{s}$. & $\begin{array}{l}\text { Vermeulen and Evans, } \\
2006\end{array}$ \\
\hline $\begin{array}{l}\text { Racing Thoroughbreds (14-26) } \\
\text { (Treadmill: 14, Track: } 26)\end{array}$ & $\begin{array}{l}\text { Single step } \\
-600 \mathrm{~m} / \mathrm{min} \text { on a } 5^{\circ} \text { inclined treadmill. } \\
-800 \mathrm{~m} \text { on the track }\end{array}$ & Evans et al., 1993 \\
\hline $\begin{array}{l}\text { Racing Thoroughbreds (5) } \\
\text { (Treadmill) }\end{array}$ & $\begin{array}{l}\text { Incremental, run to fatigue } \\
450,540,660,780,870 \mathrm{~m} / \mathrm{min} \text { at incline } 5,2 \%\end{array}$ & Guthrie et al., 1996 \\
\hline $\begin{array}{l}\text { Trotting Standardbreds } \\
\left(159,194^{*}, /\right) \\
\text { (Track) }\end{array}$ & $\begin{array}{l}\text { Incremental } \\
\text { Warm-up }(10 \mathrm{~min}-300 \mathrm{~m} / \mathrm{min}) \\
3 \times 3 \mathrm{~min} \text { with } 1 \mathrm{~min} \text { rest in between } 440 \text { to } 500 \mathrm{~m} / \mathrm{min} \text { (step } 1)+40 \\
\text { to } 80 \mathrm{~m} / \mathrm{min} \text {. each step (age-dependent) } \\
\text { *followed over } 6 \text { years: } 1105 \text { SETs }\end{array}$ & $\begin{array}{l}\text { Couroucé et al., 1997, } \\
1999,2002\end{array}$ \\
\hline $\begin{array}{l}\text { Trotting Standardbreds (223) } \\
\text { (Track) }\end{array}$ & $\begin{array}{l}\text { Incremental } \\
\text { Warm-up }(10 \mathrm{~min}-350 \mathrm{~m} / \mathrm{min}) \\
3 \times 3 \mathrm{~min}+1 \mathrm{~min} \text { rest in between } \\
500 \mathrm{~m} / \mathrm{min} \text { (step } 1)+60 \text { to } 90 \mathrm{~m} / \mathrm{min} \text {. each step (age-dependent) }\end{array}$ & Leleu et al., 2005 \\
\hline $\begin{array}{l}\text { Trotting Standardbreds (19) } \\
\text { (Track) }\end{array}$ & $\begin{array}{l}\text { Incremental } \\
\text { Warm-up }(10-15 \mathrm{~min} \text { walk, slow trot) } \\
4 \text { or more } 5 \text { min steps (varying from } 360-660 \mathrm{~m} / \mathrm{min})+3 \text { min rest in-between }\end{array}$ & Lindner, 2009 \\
\hline $\begin{array}{l}\text { Trotting Standardbreds }(10) \\
\text { (Track) }\end{array}$ & $\begin{array}{l}\text { Incremental } \\
3 \times 3 \mathrm{~min} \text { (last step chosen so HR is slightly above } 200 \mathrm{bpm} \text { ) }\end{array}$ & Hamlin et al., 2002 \\
\hline $\begin{array}{l}\text { Trotting Standardbreds ( } 48) \\
\text { (Track) }\end{array}$ & $\begin{array}{l}\text { Incremental } \\
500,583,700 \mathrm{~m} / \mathrm{min} \text { over } 1500 \mathrm{~m} \text { with } 500 \mathrm{~m} \text { in-between }\end{array}$ & Van Erck et al., 2006 \\
\hline $\begin{array}{l}\text { Trotting Standardbreds (15) } \\
\text { (Treadmill) }\end{array}$ & $\begin{array}{l}\text { Incremental } \\
\text { no acclimatization }-10 \mathrm{~min} \text { warm up } \\
4 \times 3 \mathrm{~min} \text { at } 90-240-420-540 \mathrm{~m} / \mathrm{min} \text { with a } 3 \% \text { slope. } 2 \text { min rest in-between }\end{array}$ & Wolter et al., 1991 \\
\hline $\begin{array}{l}\text { Eventing Thoroughbreds (9) } \\
\text { (Track) }\end{array}$ & $\begin{array}{l}\text { Incremental } \\
\text { warm up, } 400,500,600 \mathrm{~m} / \mathrm{min} \text { for } 1000 \mathrm{~m}+5 \mathrm{~min} \text { walking in between }\end{array}$ & Muñoz et al., 1998 \\
\hline $\begin{array}{l}\text { Eventing horses (17) } \\
\text { (Track) }\end{array}$ & $\begin{array}{l}\text { Incremental } \\
250,350,450,600 \mathrm{~m} / \mathrm{min} \text { over } 450 \mathrm{~m}+\text { brief periods of walking in between }\end{array}$ & Serrano et al., 2002 \\
\hline $\begin{array}{l}\text { Endurance and riding } \\
\text { school horses (12) } \\
\text { (Track) }\end{array}$ & $\begin{array}{l}\text { Incremental } \\
1100 \mathrm{~m} \text { at HR of } 140,150,160,170 \mathrm{bpm} \text { and HRmax. } \\
8 \text { min recovery at walk after each step }\end{array}$ & $\begin{array}{l}\text { Sloet.Van Oldruitenborgh- } \\
\text { Oosterbaan et al., } 1987\end{array}$ \\
\hline $\begin{array}{l}\text { Mixed breeds (12) } \\
\text { (Riding arena) }\end{array}$ & $\begin{array}{l}\text { Incremental } \\
\text { - Ridden test ( } 60 \mathrm{x} 40 \mathrm{~m} \text { arena): } \\
400 \mathrm{~m} \text { walk, } 600 \mathrm{~m} \text { trot, } 600 \mathrm{~m} \text { medium canter, } 800 \mathrm{~m} \text { fast canter (all on right rein) } \\
\text { - Lunging test (circle: } 5 \text { or } 7 \mathrm{~m} \text { radius): } \\
2 \text { minutes on both left and right rein in walk, trot and canter }\end{array}$ & Harris et al., 2007 \\
\hline $\begin{array}{l}11 \text { Andalusian horses, } \\
9 \text { Arabian horses, } \\
4 \text { Anglo-Arabian horses } \\
\text { (Track) }\end{array}$ & $\begin{array}{l}\text { Incremental } \\
250,333,420,500 \mathrm{~m} / \mathrm{min}\end{array}$ & Riber et al., 1994 \\
\hline $\begin{array}{l}\text { Eventing } / \text { Showjumping/ } \\
\text { Dressage Warmbloods }(\mathrm{n}=29) \\
\text { (Treadmill }-6 \% \text { incline) }\end{array}$ & $\begin{array}{l}\text { Incremental } \\
\text { Warm-up ( } 30 \mathrm{~min} \text { walk, trot, brief canter }) \text {, } \\
2 \text { steps at trot }(210 \mathrm{~m} / \mathrm{min} \text { for } 120 \mathrm{~s}-240 \mathrm{~m} / \mathrm{min} \text { for } 90 \mathrm{~s}) \\
3-5 \text { steps at gallop }(360 \mathrm{~m} / \mathrm{min} \text { and increasing with } 60 \mathrm{~m} / \mathrm{min} \text { each step })\end{array}$ & Bitschnau et al., 2010 \\
\hline $\begin{array}{l}\text { Endurance horses }(17,38) \\
\text { (Track \& Treadmill) }\end{array}$ & $\begin{array}{l}\text { Incremental } \\
\text {-Track: warm up at walk } / \text { trot, canter } 27 \mathrm{~km} \text { at } 360 \mathrm{~m} / \mathrm{min}, 1500 \mathrm{~m} \text { at } 450 \\
\text { and } 530 \mathrm{~m} / \mathrm{min}+700 \mathrm{~m} \text { slow trot in-between } \\
\text {-Tread } \mathrm{mill}: \text { warm up }(5 \mathrm{~min} \text { walk- } 5 \mathrm{~min} \text { trot }) \text {, slope } 4 \%: 3 \times 3 \text { min canter: } \\
450-490-540 \mathrm{~m} / \mathrm{min}+2 \text { min walk in-between }\end{array}$ & $\begin{array}{l}\text { Fraipont et al.,2011 \& } \\
2012\end{array}$ \\
\hline $\begin{array}{l}\text { Friesian horses (9) } \\
\text { (Track) }\end{array}$ & $\begin{array}{l}\text {-SET A: continuous cantering: warm up at walk, } 4 \text { minutes of trot } \\
\text { at } 210 \mathrm{~m} / \mathrm{min} \text { followed by } 4 \text { minutes of canter at } 300 \mathrm{~m} / \mathrm{min} \\
\text {-SET B: episodes of cantering }: 2 \text { minutes of trot at } 210 \mathrm{~m} / \mathrm{min}, 1 \mathrm{~min} \text { of } \\
\text { canter } 300 \mathrm{~m} / \mathrm{min}, 1 \mathrm{~min} \text { trot at } 210 \mathrm{~m} / \mathrm{min} \text { followed by } 1 \mathrm{~min} \text { of canter at } \\
300 \mathrm{~m} / \mathrm{min} .1 \mathrm{~min} \text { of walk, } 2 \mathrm{minutes} \text { of trot at } 210 \mathrm{~m} / \mathrm{min}, 1 \mathrm{~min} \text { of canter } \\
300 \mathrm{~m} / \mathrm{min}, 1 \mathrm{~min} \text { trot at } 210 \mathrm{~m} / \mathrm{min} \text { followed by } 1 \mathrm{~min} \text { of canter at } 300 \mathrm{~m} / \mathrm{min}\end{array}$ & Houterman et al., 2015 \\
\hline
\end{tabular}


Table 3. Overview of ideal HR to measure velocity parameters per discipline/breed.

\begin{tabular}{ll}
\hline Discipline/ breed & Ideal HR to measure velocity at \\
\hline Thoroughbred racing & V200 \\
Standardbreds trotting / pacing & V200 \\
Eventing & V140, V170, V200 \\
Show jumping horses & V170 \\
Dressage horses & V140 \\
\hline
\end{tabular}

Standardbreds with superior exercise capacity have a higher Vla4 or Vla2. These are valid parameters to assess the fitness level of standardbreds and their response to training (Wolter et al., 1991; Greppi et al., 1996; Courouce, 1999; Courouce et al., 2002). A negative correlation between Vla4 and racing time has been found (Lindner, 2009; Greppi et al., 1996), but a similar correlation could not be found for V200 (Lindner, 2009), which is probably due to the fact that heart rate is more easily influenced by for example mental state and physical discomfort and is less trainable than lactate production (Roneus et al., 1999). However, other authors found that both Vla4 and V200 are correlated with racing performance (Leleu et al., 2005). HR and blood lactic acid responses to submaximal exercise reliably reflect the muscle, cardiovascular and metabolic capacities (Mediane et al., 1997) (Figure 4).

\section{Eventing horses}

During eventing, horses run distances up to 6270 $\mathrm{m}$ with average speeds of $34.2 \mathrm{~km} / \mathrm{h}$ and up to 40 obstacles (Serrano et al., 2002; Muñoz et al., 1999). During cross country, horses show heart rates between 170-210 bpm and maximal blood lactic acid concentrations between 8.5 and $38.5 \mathrm{mmol} / \mathrm{L}$ (Munsters et al., 2014). These horses are often thoroughbreds or thoroughbred-crossbreeds. Mostly, a 3-to-4-step incremental exercise test protocol is used. An example of a commonly used protocol is: 5-10 minutes warming-up at slow trot and 3-4 times 3 minutes steps at speeds between 21-36 km/h (Hodgson et al., 2014). The most valuable indices of exercise capacity for eventing horses are V140, V170, V200, Vla4 and heart rate reserve (HRR), which is the difference between HRmax and HR at rest after a submaximal SET (Bitschnau et al., 2010; Munsters et al., 2013).

\section{Show jumpers}

Show jumping horses gallop aerobically at speeds of $18-27 \mathrm{~km} / \mathrm{h}$ between each jump with an average HR of 150-190 bpm (Sloet Van Oldruitenborgh-Oosterbaan et al., 2006). However, anaerobic pathways provide energy for the jumps, because blood lactic acid concentrations of $9 \mathrm{mmol} / \mathrm{l}$ can be achieved (Sloet Van Oldruitenborgh-Oosterbaan et al., 2006). Mostly, a similar testing exercise protocol is described for show jumping horses as for eventing horses (Hodgson et al., 2014). However, show jumping horses don't perform exercise of the same length or intensity as eventers, which often lead to a step duration reduction of three to two minutes, which might lead to not achieving a steady state in HR during the steps. A SET that takes into account several jumps to evaluate technical skills would be even more suitable (Munsters et al., 2014). As mentioned before, V170 is a more appropriate index of performance capacity than V200 as heart rates of $200 \mathrm{bpm}$ have been rarely recorded in jumping horses (Hodgson et al., 2014). Vla4 has not been correlated to show jumping results and the importance of Vla4 in show jumpers appears to be less than for instance in standardbred race horses.

\section{Dressage/ riding horses}

Dressage requires 4-8 minutes of technically demanding exercises with HRs rarely exceeding 150 bpm, which suggests the energy supply is partly aerobic during submaximal exercises, although individual muscle groups intensely contract during specific dressage movements (Williams et al., 2009). Therefore, dressage horses also need both strength and stamina. There is no specific exercise test to analyze the fitness level of dressage horses.

Submaximal exercises at low canter speed are recommended (Munsters et al., 2014). These can range from incremental exercise tests on the track (Harris et al., 2007), over indoor riding tests (Munsters et al., 2013) to lunging tests. Lunging tests do not require a galloping track nor an experienced rider, and can be easily implemented in a daily training program (Harris et al., 2007). Fitness indices like V140 correspond well and there is a clear correlation between HR and speed (Harris et al., 2007). Future SETs with theincorporation of the technical skills would be even more representative (Munsters et al., 2014). Vla4 is of less importance in horses in dressage sport than in other disciplines, since these horses use almost no anaerobic metabolism throughout dressage and training (Tables 2 and 3).

\section{DISCUSSION}

Proper assessment of the exercise capacity and training response of sport horses is of major impor- 
tance for animal welfare. It is well known that when sport horses compete at levels above their exercise capacity, sports injuries are very likely to occur. Each discipline entails that the horse needs to master a specific set of skills and needs to harbor a certain degree of aerobic and/or anaerobic exercise capacity.

In addition to the fact that each sports discipline has its own set of prerequisite performance factors, there is also growing evidence that both horse breed and age have an important impact on these parameters. Therefore, most probably, sports discipline specific SETs that can be adapted for both breed and age will need to be developed.

As illustrated in Table 2, many researchers have been extrapolating results from studies focusing on standardbreds and thoroughbreds to develop possible protocols. However, more and more studies show that this is not a good approach. Show jumping, eventing and dressage are highly important equestrian disciplines, but up till now, very little is known about the energy metabolism of horses performing these disciplines. As mentioned previously, HR and blood lactic acid monitoring in show jumping and dressage horses has revealed that these horses show much lower heart rates and blood lactic acid levels during competition than endurance horses or standardbreds used for trotting. They perform predominantly in the aerobic window, with bouts of acceleration and jumping, covered in the anaerobic window. It is quite challenging to develop SETs that cover all these aspects: checking of skills level versus optimal exercise capacity under the necessary conditions.

In the early days, exercise performance studies were solely executed on treadmills that ensure controlled conditions and thus a high reliability. However, treadmill studies have several disadvantages: horses need to be transported to a facility with a high-speed treadmill, they need to be habituated to the treadmill in order to avoid a bias, e.g. higher HR or blood lactic acid concentrations due to stress-induced adrenalinerelease, and extrapolation to the horses' disciplinespecific requirements is difficult. Moreover, horses tend to walk differently on a treadmill, which affects energy expenditure during treadmill exercise. Additionally, horses have a different head-neck position on a treadmill, which may influence air flow in the upper airways and thus in the air supply to the lungs. Several studies have shown that caution is warranted when extrapolating results obtained through treadmill exercise to field conditions (Fraipont et al., 2012; Sloet et al., 1988; Valette et al., 1992).

With the coming of more portable measuring devices, performing an exercise capacity study in the field has become quite feasible. More and more studies are being performed in field conditions. The advantage is that the horse performs under realistic, natural conditions, including being ridden or being mounted in the sulky. The disadvantage is that there are many uncontrollable factors, such as different riders/drivers and track differences between yards, but also changes in weather and track conditions in the same yard over time.

Additionally, several new monitoring devices can be used during SETs, either per telemetric or continuous measurement: telemetric body core temperature monitoring (Green et al., 2005) and continuous glucose or L-glutamate monitoring (Wiedmeyer et al. 2003, Kaimori et al., 2006; Niwa et al., 1998). Their usefulness is still to be examined. Dynamic endoscopic imaging, telemetric electrocardiography, bronchoalveolar lavage and blood analysis before and after exercise are often performed on horses showing poor performance. However, at this moment, exercise tests in horses are mostly limited to the monitoring of velocity, heart rate and lactic acid concentration. For racehorses, field tests on the track seem to be suitable as the goal of their training is to enhance speed and the distance, over which this speed can be maintained. Despite the fact that submaximal, incremental exercise tests seem less valid for sprinters, the parameters derived from these tests (VLa4 and to a lesser extent V200) may be correlated with racing performance. Single-step exercise tests with one bout seem more natural, but the results of these tests may not be correlated with racing performance. For other disciplines, such as show jumping or dressage, a simple heart rate-velocity or heart rate-lactate relationship is not sufficient. These disciplines require other skills (coordination, jumping technique) than solely a high aerobic/anaerobic capacity, which is also illustrated by the rather low heart rate recorded during training and competition.

In conclusion, because of the lacking validity of track tests and the high variability between sport disciplines, standardized tests adapted to the specific discipline, including assessment of the horses' technical skills, are to be developed in the future.

\section{REFERENCES}

Allen K., Franklin S. (2016). Exercise testing in the equine athlete. Equine Veterinary Education 28, 89-98.

Bitschnau C., Wiestner T., Trachsel D., Auer J., Weishaupt M. (2010). Performance parameters and post exercise heart rate recovery in Warmblood sports horses of different performance levels. Equine Veterinary Journal 42, 17-22.

Courouce A., (1999). Field exercise testing for assessing fitness in French standardbred Trotters. Veterinary Journal 157, 112-122.

Courouce A., Corde R., Valette J., Cassiat G., Hodgson D., Rose R. (2000). Comparison of some responses to exercise on the track and the treadmill in French trotters: determination of the optimal treadmill incline. Veterinary Journal 159, 57-63.

Couroucé A., Chrétien M., Valette J. (2002). Physiological variables measured under field conditions according to age and state of training in French Trotters. Equine Veterinary Journal 34, 91-97.

Couroucé-Malblanc A., van Erck-Westergren E. (2013). 
Exercise testing in the field. Equine Sports Medicine and Surgery. Second Edition, 25-42.

Davie A., Evans D. (2000). Blood lactate responses to submaximal field exercise tests in thoroughbred horses. Veterinary Journal 159, 252-258.

Dubreucq C., Chatardt J., Courouce A., Auvinet B. (1995). Reproducibility of a standardised exercise test for Standardbred trotters under field conditions. Equine Veterinary Journal 27, 108-112.

Eto D., Yamano S., Hiraga A., Miyata H. (2006). Recruitment pattern of muscle fibre type during flat and sloped treadmill running in Thoroughbred horses. Equine Veterinary Journal 38, 349-353.

Evans D., Harris R., Snow D. (1993). Correlation of racing performance with blood lactate and heart rate after exercise in Thoroughbred horses. Equine Veterinary Journal $25,441-445$.

Evans D. (2000). Training and fitness in athletic horses. $R u$ ral Industries Research and Development Corporation Rural Industries Research and Development Corporation Publications. 00/1

Evans D. (2007). Physiology of equine performance and associated tests of function. Equine Veterinary Journal 39, 373-383.

Fraipont A., Van Erck E., Ramery E., Richard E., Denoix J. (2011). Subclinical diseases underlying poor performance in endurance horses: diagnostic methods and predictive tests. Veterinary Record 169, 154.

Fraipont A., Van Erck E., Ramery E., Fortier G., Lekeux P., Art T. (2012). Assessing fitness in endurance horses. Canadian Veterinary Journal 53, 311-314.

Franklin S., Allen K. (2014). Laboratory exercise testing. Equine Sports Medicine and Surgery. Second Edition, p 11-24.

Gramkow H., Evans D. (2006). Correlation of race earnings with velocity at maximal heart rate during a field exercise test in Thoroughbred racehorses. Equine Veterinary Journal 36, 118-122.

Green A., Gates R., Lawrence L. (2005). Measurement of horse core body temperature. Jourmal of Thermal Biology 30, 370-377.

Greppi G., Casini L. (1996). Correlation racing performance with fitness parameters after exercise tests on treadmill and on track in Standardbred racehorses. Pferdekeilkunde 12, 466-469.

Guthrie A., Lund R., Travers C. (1996). Characterization of a standard exercise to fatigue test in Thoroughbred horses. Pferdeheilkunde 12, 463-465.

Hamlin M., Shearman J., Hopkins W. (2002). Changes in physiological parameters in overtrained Standardbred racehorses. Equine Veterinary Journal 34, 383-388.

Harkins J., Beadle R., Kamerling S. (1993). The correlation of running ability and physiological variables in Thoroughbred racehorses. Equine Veterinary Journal 25, 5360.

Harris P., Marlin D., Davidson H., Rodgerson J., Gregory A., Harrison D. (2007). Practical assessment of heart rate response to exercise under field conditions. Equine Comparative Exercise Physiology 4, 15-21.

Hodgson D., Couroucé-Malblanc A. (2014). Clinical exercise testing. The Athletic Horse. Second Edition, p 366-374.

Houterman W. (2015). Monitoring blood lactate and heart rate during two different standardised exercise tests in young Friesian horses, Masterthesis Faculty of Veterinary Medicine, Utrecht.
Kaimori S., Kitamura T., Ichino M., et al., (2006). Structural development of a minimally invasive sensor chip for blood glucose monitoring. Analytica chimica acta 573, 104-109.

Kobayashi M., Kuribara K., Amada A. (1999) Application of V200 values for evaluation of training effects in the young Thoroughbred under field conditions. Equine Veterinary Journal 30, 159-162.

Leleu C., Cotrel C., Couroucé-Malblanc A. (2005). Relationships between physiological variables and race performance in French Standardbred trotters. Veterinary Record 156, 339-342.

Lindner A. (2009). Relationships between racing times of Standardbreds and v4 and v 200. Journal of Animal Science 88, 950-954.

Mediane V., Science A., Persson S. (1997). Heart rate and blood lactate responses to submaximal treadmill exercise in the normally performing standardbred trotter - age and sex variations and predictability from the total red blood cell volume. Journal Veterinary Medicine 44, 125-132.

Muñoz A., Riber C., Santisteban R., Vivo R., Agüera S., Castejón F. (1998). Investigation of standardized exercise tests according to fitness level for three-day event horses. Journal of Equine Science 9, 1-7.

Muñoz A., Riber C., Santisteban R., Agüera E., Rubio M. (1999). Cardiovascular and metabolic adaptations in horses competing in cross-country events. Journal Veterinary Medicine Science 61, 13-20.

Munsters C., Van Den Broek J., Welling E., Van Weeren R., Van Oldruitenborgh-oosterbaan M. (2013). A prospective study on a cohort of horses and ponies selected for participation in the European Eventing Championship: reasons for withdrawal and predictive value of fitness tests. $B M C$ Veterinary Research 9, 1-11.

Munsters C., van Iwaarden A., van Weeren R., Sloet van Oldruitenborgh-Oosterbaan M. (2014). Exercise testing in Warmblood sport horses under field conditions. Veterinary Journal 202, 11-19.

Niwa O., Horiuchi T., Kurita R., et al. (1998). Microfabricated on-line sensor for continuous monitoring of 1-glutamate. Analytical Sciences 14, 947-953.

Riber C., Castejon F., Rubio D., Tovar P., Vinuesa M. (1994). A comparative study of aerobic capacity and fitness in three different horse breeds (Andalusian, Arabian and Anglo- Arabian). Journal of Veterinary Medicine 41, 645-652.

Roneus N., Lindholm A., Essen-Gustavsson B., Persson S. (1999). Muscle characteristics and plasma lactate and ammonia response after racing in Standardbred trotters: relation to performance. Equine Veterinary Journal 31, 170-173.

Seeherman H., Morris E. (1990). Methodology and repeatability of a standardised treadmill exercise test for clinical evaluation of fitness in horses. Equine Veterinary Journal 22, 20-25.

Serrano M., Evans D., Hodgson J. (2002). Heart rate and blood lactate responses during exercise in preparation for eventing competition. Equine Veterinary Journal Supplements 34, 135-139.

Sloet Van Oldruitenborg-Oosterbaan M, Wensing T., Breukink H. (1987). Standardized exercise test on a track to evaluate fitness and training of saddle horses. ICEEP Conference.

Sloet van Oldruitenborgh-Oosterbaan M., van den Hoven R., Breukink H. (1988). The accuracy of three different 
heart rate meters used for studies in the exercising horse. Journal Veterinary Medicine 35, 665-672.

Sloet Van Oldruitenborgh-Oosterbaan M., Spierenburg A., Van den Broek E. (2006). The workload of riding-school horses during jumping. Equine Veterinary Journal 38, 93-97.

Valette J., Barrey E., Auvinet B., Galloux P., Wolter R. (1992). Comparison of track and treadmill exercise tests in saddle horses: a preliminary report. Annales de Zootechnie 41, 129-135.

Van Erck E., Jakesova V., Lekeux P., Art T. (2006) Field evaluation of poor performance in Standardbred trotters. Pferdeheilkunde 22, 625-631.

Van Erck E., Votion DM., Serteyn D., Art T. (2007). Evaluation of oxygen consumption during field exercise tests in Standardbred trotters Equine and Comparative Exercise Physiology 4, 43-49.

Vermeulen A., Evans D. (2006). Measurements of fitness in Thoroughbred racehorses using field studies of heart rate and velocity with a global positioning system. Equine Veterinary Journal 36, 113-117.

Von Wittke P., Deegen E., Lidner A., Ommer H. (1994). Effects of training on blood lactate-running in thoroughbred racehorses speed relationship. Journal of Applied Physiology 77, 298-302.

Williams R., Chandler R., Marlin D. (2009). Heart rates of horses during competitive dressage. Comparative Exercise Physiology 6, 7-15.

Wiedmeyer C., Johnson P., Cohn L., et al. (2003). Evaluation of a continuous glucose monitoring system for use in dogs, cats, and horses. Journal of the American Veterinary Medical Association 223.7, 987-992.

Wolter R., Valette J., Barrey E. (1991). Multivariate analysis of exercise parameters measured during an incremental treadmill test. Equine Exercise Physiology 3, 337-342.

Wolter R., Valette J., Heiles P. (1996). Multivariate analysis of exercise parameters measured during the training of Thoroughbred racehorses. Pferdekeilkunde 12, 470-473.

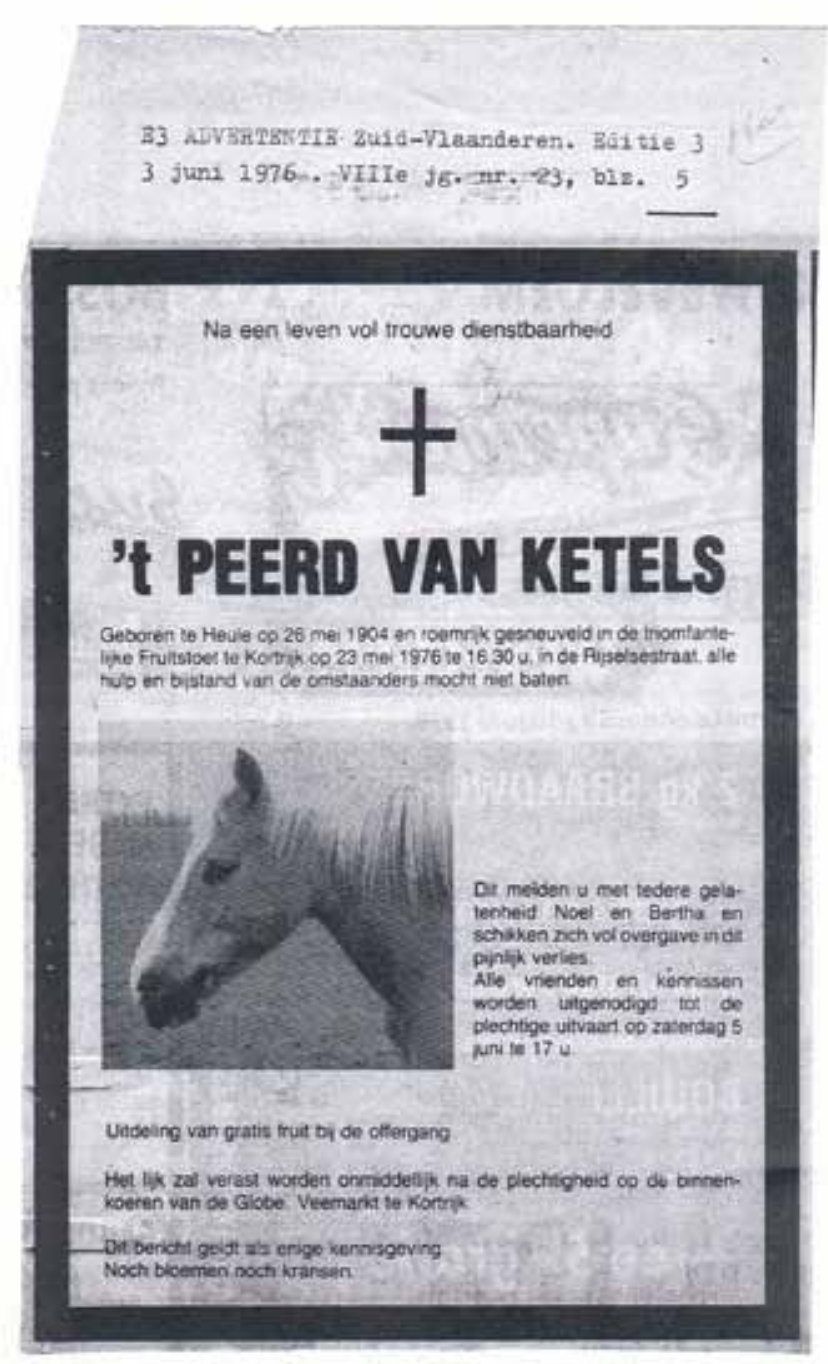

